\title{
Impact of Cannabis on the Port of Entry-Oral Tissues: An Overview
}

\author{
Harpreet Singh*, Joseph Katz, Wafaa Saleh and Seunghee Cha \\ Department of Oral and Maxillofacial Diagnostic Sciences, College of Dentistry, University of Florida, USA
}

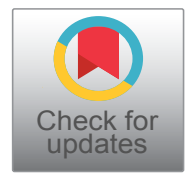

*Corresponding author: Dr. Harpreet Singh, Department of Oral and Maxillofacial Diagnostic Sciences, College of Dentistry, University of Florida, Gainesville, FL 32610, USA, Tel: 352-273-6685, Fax: 352-846-0588

\begin{abstract}
Objective: While there is a recent surge in the publications describing the beneficial effects of cannabis in chronic pain control and anti-seizure effects there is a dearth of reporting on the potential side effects of marijuana particularly in the oral cavity. Since the oral cavity is the main port of entry of cannabis, the aim of this review paper is to inform and educate importance to the dental professionals and public about the negative effects of chronic cannabis use in the oral cavity.
\end{abstract}

Literature search: Studies published in the English language on PubMed, Web of Science, Wiley Library and Springer reported from 1978to 2018 including human studies, animal studies, and case reports.

Results: The continuous use of cannabis was associated with adverse effects on oral tissues such as increased xerostomia and caries incidence, periodontal and gingival problems, oral cancer and candidiasis. The compound 9-tetrahydrocannabinol was implicated with most of these adverse effects.

Conclusion: The literature review has identified a wide range of detrimental effects in the oral cavity when cannabis is used chronically.

\section{Keywords}

Cannabis, Marijuana, Xerostomia, Oral cancer, Caries, Periodontal diseases

\section{Introduction}

The use of cannabis is very common in the western world and in the USA in particular ${ }^{\circledR}$. The source of cannabis sativa (C. sativa) a plant from the cannabaceae originally from Central and Eastern Asia. Marijuana is the most common psychoactive medication utilized in America and around the globe [1]. Current data shows that roughly 147 million individuals $(2.5 \%)$ on planet earth utilize cannabis for various reasons [2]. The predominance of marijuana abuse among the elderly population in the USA (matured $\geq 65$ ) shows uprising, and developing association is evident of complications in oral cavity due to cannabis abuse [3]. In the current scenario, cannabis use in on the rise with legalization in a few states, and pending enactment in others. Ample evidence has been reported in the literature supporting the advantages of cannabinoids for an extensive variety of medical conditions for pain and agony for specific diseases, such as AIDS, glaucoma, and treatment of neurological ailments including epilepsy, however, concerns have emerged with respect to the potential abuse and additionally hazardous utilization of cannabinoids.

The fundamental driver of the antagonistic impacts caused by 9-tetrahydrocannabinol (THC) a synthetic compound found in cannabis [4]. The mechanism through which this active component signal is through cell-surface receptors specific to cannabinoid receptors 1 (CB1) in the cerebrum, lungs, liver, and kidneys and cannabinoid receptors 2 (CB2) in the immunity system and hematopoietic cells [5]. The cannabinoids contrarily influence the immunity reaction and harm the host defense against microbial infections [6].

\section{Literature Search}

The following search keywords were used: (Cannabis), (Cannabinoid), (Marijuana), (Hash oil), and its impact on (Periodontal), (Gingival) tissues, (Dental caries), (Xerostomia) and (Oral) or (Oropharyngeal cancer). The search was done in August 2018 on PubMed, Web of Science, Scopus, Wiley online library and Springer library and included human studies, experimental studies, and case reports written in English and published from 1978 and 2018. No filters were applied amid the search procedure and, subsequently, any published

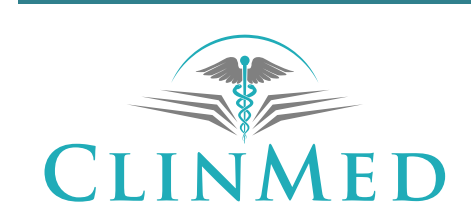

INTERNATIONAL LIBRARY 
study qualified for incorporation in this paper.

\section{Results}

From 5638 query items, eighteen investigations were qualified including five experimental studies, eleven case-control studies, two prospective cohort, and 5 case reports were added due to the limited number of published eligible studies. The research revealed an aggregate of 5638 publications in databases and duplicated articles were removed. These investigations and research papers demonstrated the chronic utilization of cannabis lead to antagonistic impacts in the mouth, for example, gingival and periodontal issues, oral cancer, xerostomia, dental caries, and candidiasis. All these clinical studies and their finding are briefly incorporated in Table 1.

\section{Discussion}

Since ages, the most traditional and common method of marijuana use is smoking of dried leaves of cannabis sativa. In recent times other methods are also becoming quite popular for instance "vaping" which is inhaling vaporized dried flowers or cannabis oil and "ed- ibles" in which person takes cannabis as an ingredient in edible products [7]. The other methods of marijuana consumption are inhaling vaporized THC oil commonly called as "shatter" and "wax" with a process called "dabbing" [8]. Medical cannabis is also well known for its anti-nociceptive and antihyperalgesic effects in the peripheral and central nervous system [9]. The port of entry for all forms of cannabis which are volatile, edible, medicinal, non-medicinal is the oral cavity which may be affected in an adverse way. The purpose of the present review is to summarize the short term and long term adverse effects of recreational marijuana on the oral cavity. The limitation of this review is that based on literature search we are not able to establish that adverse effects of cannabis are most commonly related to which form of cannabis as there is not much of literature available on the individual cannabis forms and their adverse effects.

\section{Impact on Periodontium}

As reported by López $R$, et al. cannabis smoking is a hazard factor for the periodontal disease that is independent of the use of tobacco [10]. Studies conducted

Table 1: Showing adverse effects with chronic use of cannabis in the oral cavity. Impacts with chronic use of cannabis in the oral cavity.

\begin{tabular}{|c|c|c|}
\hline $\begin{array}{l}\text { Oral } \\
\text { conditions }\end{array}$ & Clinical findings & Authors \& References \\
\hline Oral cancer & $\begin{array}{l}\text { Oral papilloma, leukoplakia and erythroplakia, } \\
\text { cannabis stomatitis, HPV-positive oropharyngeal } \\
\text { cancer. }\end{array}$ & $\begin{array}{l}\text { Darling and Arendorf [11] } \\
\text { Aldington, et al. [23] } \\
\text { Feng, et al. [24] } \\
\text { Liang, et al. [29] } \\
\text { Tashkin, et al. [25] } \\
\text { Wu, et al. [26] } \\
\text { Gillison, et al. [28] } \\
\text { Flygare and Sander [30] }\end{array}$ \\
\hline $\begin{array}{l}\text { Periodontal } \\
\text { diseases }\end{array}$ & $\begin{array}{l}\text { Fiery red gingivitis, gingival leukoplakia, gingival } \\
\text { inflammation, and alveolar bone loss. } \\
\text { Greater probing depth, Attachment loss, High risk of } \\
\text { developing periodontitis. } \\
\text { Severe periodontitis. }\end{array}$ & $\begin{array}{l}\text { Lopez and Baelum [10] } \\
\text { Darling and Arendorf [11] } \\
\text { Nogueira-Filho [15] } \\
\text { JA Shariff, KP Ahluwalia and PN Papapanou [17] }\end{array}$ \\
\hline $\begin{array}{l}\text { Gingival } \\
\text { enlargement }\end{array}$ & $\begin{array}{l}\text { Blazing gingivitis, gingival overgrowth, Rugged } \\
\text { gingiva, Attachment loss. }\end{array}$ & $\begin{array}{l}\text { Baddour, et al. [19] } \\
\text { Rawal, et al. [20] } \\
\text { Momen-Heravi and Kang [21] }\end{array}$ \\
\hline Xerostomia & $\begin{array}{l}\text { Oral dryness, bad taste, loss of teeth. } \\
\text { Reduced parotid salivary flow. }\end{array}$ & $\begin{array}{l}\text { Versteeg, et al. [2] } \\
\text { Kopach, et al. [34] } \\
\text { Darling and Arendorf [22] } \\
\text { Schulz-Katterbach, Imfeld and Imfeld [35] } \\
\text { Pikkarainen, et al. [36] } \\
\text { F Di Cugno, CJ Perec and AA Tocci [37] }\end{array}$ \\
\hline Dental decay & Higher DMF index or plaque score. & $\begin{array}{l}\text { Darling and Arendorf [8] } \\
\text { Schulz-Katterbach [35] } \\
\text { Silverstein S [38] }\end{array}$ \\
\hline Candidiasis & $\begin{array}{l}\text { Increased prevalence, higher risk with } \\
\text { immunosuppression, poor denture cleanliness and } \\
\text { nutrition. }\end{array}$ & $\begin{array}{l}\text { Darling, Arendorf and Coldrey [39] } \\
\text { Warnakulasuriya [40] } \\
\text { Darling and Arendorf [22] }\end{array}$ \\
\hline
\end{tabular}


by Darling MR, et al. [11,12] have demonstrated that antagonistic impacts are not only limited to fiery red gingivitis but also seen as gingival leukoplakia, gingival hyperplasia, and alveolar bone loss [11,12]. In 1992, Darling and Arendorf also stated that a greater plaque index; and poorer gingival health is more prevalent in cannabis users than in healthy controls [11]. The mechanism by which cannabinoids negatively affects the periodontium is very well explained by Nakajima, et al. [13] According to the author's presence of CB1 and CB2 in periodontal tissue results in periodontitis with the cannabinoids present in cannabis. This effect of cannabinoids has further enhanced a surge in anandamide which is an agonist of the cannabinoid receptor obtained from arachidonic acid [13]. Thomson, et al. also documented that cannabis smoking to be a major risk factor for periodontal disease [14].

Nogueira-Filho also showed a similar type of behavior of $C$. sativa in the cancellous bone around titanium inserts of implants, in which harmful effects of $C$. Sativa on the bone repair and healing was reported [15]. In another experiment Nogueira-Filho, reported that cannabis smoke may affect alveolar bone by increasing bone loss in the ligature-incited periodontitis demonstrated in rodent [16].

In another study conducted by Shariff, et al. [17] on 1,938 subjects shows that recreational cannabis abuse is associated with deep probing depths, more clinical attachment loss and greater risk of having severe periodontitis [17].

Interestingly, other researchers are of a contrary point of view, Napimoga $\mathrm{MH}$, et al. reported that cannabinoids decrease bone resorption by restricting RANK/ RANKL and inflammation-inducing cytokines [18].

\section{Gingival Enlargement}

Many researchers such as Layman and Baddour, et al. have documented the relationship between chronic marijuana use and gingival overgrowth [19]. Rawal, et al. also described similar findings of the rugged appearance of the gingiva, without attachment loss in two individuals who were chronic marijuana users [20]. Momen-Heravi, et al. [21] published a case where an individual with chronic cannabis abuse was associated with moderate to serious attachment loss and peripheral gingival overgrowth, which was more obvious in the anterior mandible [21].

\section{Oral Mucosal Changes \& Cancer}

Various case-control studies have explored that cannabis can play a major role in causing oral malignancy. It has been reported in the literature marijuana to be related to dysplastic changes inside the epithelial cells of the buccal mucosa. These changes resulted in the increased presence of immature cells, high molecular pleomorphism and increased mitotic division and vari- ations from the normal [11]. Smoking cannabis was related to premalignant lesions in the oral cavity such as leukoplakia and erythroplakia. Chronic smoking and chewing may also result in abnormal oral epithelial changes, namely "cannabis stomatitis", which includes buccal mucosal leukoedema along with hyperkeratosis. "Cannabis stomatitis" was reported as the constant aggravation of the epithelial cells in the oral cavity resulting in leukoplakia, which may advance to neoplasia [11].

Marijuana smoking is additionally known to be involved in oral papilloma lesions. The association of papillomavirus and marijuana smoke can be identified as a suppressed immune system; however, the human papillomavirus may also be considered independently a risk factor for oral cancer development [22].

There are conflicting reports on the effects of cannabis on oral cancers. Some investigators have demonstrated that marijuana users are at higher risk for oral cancer $[23,24]$. Carcinogen also knew to get deposited with smoking marijuana in the upper respiratory tract and the mouth may increase the risks of carcinoma $[25,26]$. Smoking marijuana was also reported as a risk factor for tongue carcinoma in a published article by Almadori G, et al. [27].

In 2008, another case-control study demonstrated that using cannabis, was firmly connected with the higher chances of HPV-positive oropharyngeal malignancy [28]. Marks, et al. [29] published nine case-control studies from the USA and South America. They examined the relationship between use of marijuana and tumors of the oral cavity, pharynx, and tongue. Cannabis users were at higher risk of development of oropharynx cancer (adjusted odds ratio [a OR]: 1.24; 95\% confidence interval $[\mathrm{Cl}]: 1.06,1.47)$ and a decreased chances of malignant growth in tongue (an OR: 0.47; 95\% Cl: 0.29, 0.75) [29]. While marijuana smoke is known to have $50 \%$ more carcinogens such as benzopyrene, nitrosamines, and aromatic hydrocarbons in comparison to tobacco smoke [29].

However, few reports have a demonstrated opposite effects with cannabis use such as anti-cancer impact influencing the cell life, ceasing uncontrolled cell development, favoring programmed cell death, vascular regeneration, and cell relocation [30]. Similar results were shown by another report published by Liang C, et al. in which they proposed that moderate cannabis use can have a defensive impact [31]. In 2004, in a case-controlled study analyzed the hazard factors for oral disease, found no huge hazard for oral malignant growth [32]. de Carvalho, et al. [33] conducted a systemic review with meta-investigation of nine case-control, to show occurrence head and neck cancer in patients who use the cannabis for their entire life. They found that about $12.6 \%$ of cases and $14.3 \%$ of controls were marijuana users. However, this investigation found that there is no concrete evidence of association among chronic mari- 
juana users and oral cancer development [33], rather this study demonstrated an anti-cancer effect on cell cycle, restraining unregulated cell development [33].

\section{Xerostomia}

Cannabis is a medication with para-sympatholytic properties and consequently can result in xerostomia. It has been accounted that constant dry mouth, loss of teeth and the absence of saliva may interfere with speech, mastication, and quality of life. Studies demonstrated that the prevalence of dry mouth after cannabis use unquestionably higher in contrast with cigarette smoking controls [2]. This substance is also known to inhibit the release of different neurotransmitters including acetylcholine both centrally and peripherally [34]. A study led by Darling, et al. demonstrated that xerostomia was experienced by $69.6 \%$ of its users subsequent to marijuana smoking, contrasted with $18.6 \%$ of the tobacco smoking controls. Additionally, the impacts of xerostomia started right after the marijuana use and the span of the impacts was variable between users [24]. Analysts also mentioned in a study that cannabis abusers generally encounter xerostomia from 1-6 hours after the consumption of marijuana [35]. Oral dryness and halitosis have likewise been recorded with marijuana use by Pikkarainen, et al. [36]. In another study conducted on 198 individuals by Di Cugono, also proved similar results that cannabis did reduce parotid salivary flow. The results did reveal that the $\mathrm{pH}$ of the individuals who used marijuana was 6.90, on the other hand, the $\mathrm{pH}$ of the controls was 7.51 [37].

\section{Dental Caries}

Cannabis abusers were reported to have poorer oral status compared to the control group with higher decayed, missing and filled (DMF) teeth scores, higher plaque scores, and effected gingival health according to the study done by Rawal, et al. [11]. A group of 206 high-cannabis-users subjects was chosen $(82 \%$ of the subjects had used cannabis for approximately 1000 days), the control group had a considerably lower number of DMF-S scores, plaque scores [38]. Darling, and Arendorf [11] demonstrated a higher DMF score, a high plaque Index, and poorer gingival health in cannabis users than in nonusers [11]. An examination directed by Schulz-Katterbach assessed the impact of marijuana use and the odds of the inception of dental caries. The standard cannabis users had visited dental practitioners less frequently and had a higher plaque index. In addition, the buffering capacity of salivation was reported to be decreased in cannabis smokers [35].

\section{Candidiasis}

Darling, et al. [39] demonstrated that there was an increased prevalence of Candida among cannabis users Darling [39]. Warnakulasuriya also reported that cannabis abusers showed a higher predominance of Candida albicans when contrasted with tobacco smok- ers, because of both an immediate impact of the cannabinoids and behavior issues [40]. Darling, et al. detailed that high predominance of Candida albicans in chronic cannabis users might be related with suppressed local immune response, poor denture cleanliness, and nutrition [22] and aromatic hydrocarbons in cannabis, which acts as an energy source for some Candida infection [39].

\section{Summary}

The increasing prevalence of cannabis users in the world demands the attention of oral health care providers of the diverse adverse effects of cannabis abuse. We performed a systemic review of published data about the harmful effect of cannabis on oral tissues to increase the awareness of the patients and oral health care providers.

\section{References}

1. Grafton SE, Huang PN, Vieira AR (2016) Dental treatment planning considerations for patients using cannabis: A case report. J Am Dent Assoc 147: 354-361.

2. Versteeg PA, Slot DE, van der Velden U, van der Weijden GA (2008) Effect of cannabis usage on the oral environment: A review. Int J Dent Hyg 6: 315-320.

3. Le A, Palamar JJ (2019) Oral health implications of increased cannabis use among older adults: Another public health concern? J Subst Use 24: 61-65.

4. Ashton CH (2001) Pharmacology and effects of cannabis: A brief review. Br J Psychiatry 178: 101-106.

5. Grotenhermen F (2004) Pharmacology of cannabinoids. Neuro Endocrinol Lett 25: 14-23.

6. Do Y, McKallip RJ, Nagarkatti M, Nagarkatti PS (2004) Activation through cannabinoid receptors 1 and 2 on dendritic cells triggers NF-kappaB-dependent apoptosis: Novel role for endogenous and exogenous cannabinoids in immunoregulation. J Immunol 173: 2373-2382.

7. Schauer GL, King BA, Bunnell RE, Promoff G, McAfee TA (2016) Toking, vaping, and eating for health or fun: Marijuana use patterns in adults, U.S., 2014. Am J Prev Med 50: 1-8.

8. Loflin M, Earleywine M (2014) A new method of cannabis ingestion: The dangers of dabs? Addict Behav 39: 14301433.

9. Meng $\mathrm{H}$, Johnston $B$, Englesakis M, Moulin DE, Bhatia A (2017) Selective cannabinoids for chronic neuropathic pain: A systematic review and meta-analysis. Anesth Analg 125: 1638-1652.

10. López R, Baelum V (2009) Cannabis use and destructive periodontal diseases among adolescents. J Clin Periodontol 36: 185-189.

11. Darling MR, Arendorf TM (1992) Review of the effects of cannabis smoking on oral health. Int Dent J 42: 19-22.

12. Darling MR (2003) Cannabis abuse and oral health care: Review and suggestions for management. SADJ 58: 189190.

13. Nakajima Y, Furuichi Y, Biswas KK, Hashiguchi T, Kawahara $\mathrm{K}$, et al. (2006) Endocannabinoid, anandamide in gingival tissue regulates the periodontal inflammation through NFkappaB pathway inhibition. FEBS Lett 580: 613-619. 
14. Thomson WM, Poulton R, Broadbent JM, Moffitt TE, Caspi A, et al. (2008) Cannabis smoking and periodontal disease among young adults. JAMA 299: 525-531.

15. Nogueira-Filho Gda R, Cadide T, Rosa BT, Neiva TG, Tunes R, et al. (2008) Cannabis sativa smoke inhalation decreases bone filling around titanium implants: A histomorphometric study in rats. Implant Dent 17: 461-470.

16. Nogueira-Filho GR, Todescan S, Shah A, Rosa BT, Tunes Uda R, et al. (2011) Impact of cannabis sativa (marijuana) smoke on alveolar bone loss: A histometric study in rats. $J$ Periodontol 82: 1602-1607.

17. Shariff JA, Ahluwalia KP, Papapanou PN (2017) Relationship between frequent recreational cannabis (marijuana and hashish) use and periodontitis in adults in the United States: National health and nutrition examination survey 2011 to 2012. J Periodontol 88: 273-280.

18. Napimoga MH, Benatti BB, Lima FO, Alves PM, Campos $A C$, et al. (2009) Cannabidiol decreases bone resorption by inhibiting RANK/RANKL expression and pro-inflammatory cytokines during experimental periodontitis in rats. Int Immunopharmacol 9: 216-222.

19. Baddour HM, Audemorte TB, Layman FD (1984) The occurrence of diffuse gingival hyperplasia in a patient using marijuana. J Tenn Dent Assoc 64: 39-43.

20. Rawal SY, Tatakis DN, Tipton DA (2012) Periodontal and oral manifestations of marijuana use. J Tenn Dent Assoc 92: 26-31.

21. Momen-Heravi F, Kang P (2017) Management of cannabisinduced periodontitis via resective surgical therapy: A clinical report. J Am Dent Assoc 148: 179-184.

22. Darling MR, Arendorf TM (1993) Effects of cannabis smoking on oral soft tissues. Community Dent Oral Epidemiol 21: 78-81.

23. Aldington S, Harwood M, Cox B, Weatherall M, Beckert $\mathrm{L}$, et al. (2008) Cannabis use and cancer of the head and neck: Case-control study. Otolaryngol Head Neck Surg 138: $374-380$.

24. Feng BJ, Khyatti M, Ben-Ayoub W, Dahmoul S, Ayad M, et al. (2009) Cannabis, tobacco and domestic fumes intake are associated with nasopharyngeal carcinoma in North Africa. Br J Cancer 101: 1207-1212.

25. Tashkin DP, Calvarese BM, Simmons MS, Shapiro BJ (1980) Respiratory status of seventy-four habitual marijuana smokers. Chest 78: 699-706.

26. Wu TC, Tashkin DP, Djahed B, Rose JE (1988) Pulmonary hazards of smoking marijuana as compared with tobacco. N Engl J Med 318: 347-351.

27. Almadori G, Paludetti G, Cerullo M, Ottaviani F, D'Alatri L
(1990) Marijuana smoking as a possible cause of tongue carcinoma in young patients. J Laryngol Otol 104: 896-899.

28. Gillison ML, D'Souza G, Westra W, Sugar E, Xiao W, et al. (2008) Distinct risk factor profiles for human papillomavirus type 16-positive and human papillomavirus type 16-negative head and neck cancers. J Natl Cancer Inst 100: 407-420.

29. Marks MA, Chaturvedi AK, Kelsey K, Straif K, Berthiller $J$, et al. (2014) Association of marijuana smoking with oropharyngeal and oral tongue cancers: Pooled analysis from the INHANCE consortium. Cancer Epidemiol Biomarkers Prev 23: 160-171.

30. Flygare J, Sander B (2008) The endocannabinoid system in cancer-potential therapeutic target? Semin Cancer Biol 18: 176-189.

31. Liang C, McClean MD, Marsit C, Christensen B, Peters E, et al. (2009) A population-based case-control study of marijuana use and head and neck squamous cell carcinoma. Cancer Prev Res 2: 759-768.

32. Rosenblatt KA, Daling JR, Chen C, Sherman KJ, Schwartz SM (2004) Marijuana use and risk of oral squamous cell carcinoma. Cancer Res 64: 4049-4054.

33. de Carvalho MF, Dourado MR, Fernandes IB, Araújo CT, Mesquita AT, et al. (2015) Head and neck cancer among marijuana users: A meta-analysis of matched case-control studies. Arch Oral Biol 60: 1750-1755.

34. Kopach O, Vats J, Netsyk O, Voitenko N, Irving A, et al. (2012) Cannabinoid receptors in submandibular acinar cells: Functional coupling between saliva fluid and electrolytes secretion and Ca2+ signalling. J Cell Sci 125: 1884-1895.

35. Schulz-Katterbach M, Imfeld T, Imfeld C (2009) Cannabis and caries-does regular cannabis use increase the risk of caries in cigarette smokers? Schweiz Monatsschr Zahnmed 119: 576-583.

36. Pikkarainen $\mathrm{PH}$, Baraona $\mathrm{E}$, Jauhonen $\mathrm{P}$, Seitz HK, Lieber CS (1981) Contribution of oropharynx microflora and of lung microsomes to acetaldehyde in expired air after alcohol ingestion. J Lab Clin Med 97: 631-636.

37. Di Cugno F, Perec CJ, Tocci AA (1981) Salivary secretion and dental caries experience in drug addicts. Arch Oral Biol 26: 363-367.

38. Silverstein SJ, Noel D, Heilbron D (1978) Social drug use/ abuse and dental disease. J Calif Dent Assoc 6: 32-37.

39. Darling MR, Arendorf TM, Coldrey NA (1990) Effect of cannabis use on oral candidal carriage. J Oral Pathol Med 19: 319-321.

40. Warnakulasuriya $S$ (2009) Causes of oral cancer-an appraisal of controversies. Br Dent J 207: 471-475. 